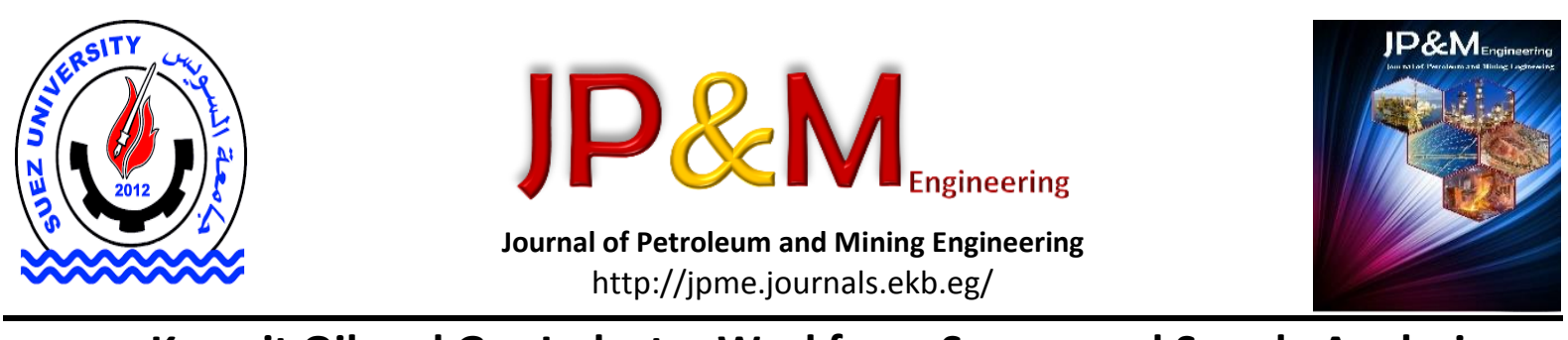

\title{
Kuwait Oil and Gas Industry Workforce Source and Supply Analysis
}

\author{
Mohamed Bizanti, ${ }^{a^{*}}$ Muhammad Alrumah ${ }^{a}$ \\ aPetroleum Engineering Technology Department, College of Technological Studies, Public Authority for Applied Education and Training, \\ Kuwait city, Kuwait \\ *Corresponding author e-mail:mobiza51@gmail.com
}

\section{Article Info}

Received 6 Nov. 2019

Revised 22 Feb. 2020

Accepted 5 Mar. 2020

\section{Keywords}

Workforce; petroleum assistant engineering; kuwait oil industry; petroleum college enrolment

\begin{abstract}
The oil and gas industry human resources typically comprise of managers, engineers, assistant engineers and, administrators among others. This paper examines the key sources of the workforce that run Kuwait's oil and gas industry. Most of the technical workforces including engineers and assistant engineers are originally from Kuwait University and the College of Technological Studies in Kuwait. This paper examines data on the number of assistant engineers in the oil and gas sector that graduated from the college of technological studies from 2006 to 2018. The college's petroleum engineering technology department was started in 2001. Remarkably, its first batch of students graduated as assistant engineers two and a half years down the line with most of them joining companies in the oil and gas sector. The college offers two programs focusses on the production and exportation while the other one focusses on exploration and development. Additionally, this paper examines the number of students that have successfully graduated from the college's petroleum engineering department over the last twelve years. Records indicate that between 2006 and 2018, about 7\% of the institution's graduates were from the petroleum engineering department.
\end{abstract}

Moreover, the study established that there was no correlation between oil prices and the number of graduates from the petroleum department. The findings of this study will be insightful to decision-makers especially in crafting policies to improve college enrolment to fill the existing workforce gap in the oil and gas sector in Kuwait.

\section{Introduction}

Petroleum engineering is a wide field of engineering that is primarily involved with the exploration, development, production, and export of oil and gas. Companies in the petroleum and gas sector need experts in petroleum engineering to assist geologists and engineers in undertaking activities in the field, lab, and office. The petroleum engineering department in the college of technological studies offers two programs in the oil and gas field. Students can either choose to specialize in exploration and development or production and export. Upon successful completion of either of the programs, graduates can be employed in the oil and gas sector as assistant engineers or technical personnel.

A study on petroleum engineering education pointed out the significance of this field to the oil and gas industry and drew special attention to the fact that the lack of regulation on the number of graduates each year could lead to a flooded job market [1]. Petroleum engineering programs are more challenging than other academic programs offered in college, however, these programs usually have higher payoffs. Strikingly, despite the prevailing oil crisis and the increased use of renewable sources of energy, petroleum engineering is still the highest paying field of engineering. It is reported that a petroleum engineer earns an average of $\$ 134,000$ per annum while a petroleum technician earns an average of $\$ 60,000$ per annum [2]. According to the Bureau of Labour (2015), petroleum and geological technicians assist engineers and geologists to explore and extract natural resources like natural gas, oil, and minerals [3]. Petroleum and geological technicians can work in the field, labs and offices with most of them working full time. To become a petroleum or geological technician, one must have to an associate degree or successfully complete a two-year post-secondary 
training program in applied science or any sciencerelated program. In May 2016, the annual median wage for petroleum and geological technicians was $\$ 56,470$ even though the annual average salary for petroleum engineers in the same year was approximately $\$ 112,000$ [3].

The declining oil prices negatively affect petroleum engineering graduates [4]. However, employment opportunities for petroleum and geological technicians is expected to increase by $12 \%$ between 2014 and 2024. This can be attributed to the increasing demand for natural gas that the increasing need for experts to help in exploration and extraction activities. A study was carried out at the Kuwait University to determine how demographic variables influence motivation among male and female students [5]. The scholar also investigated the effect of demographic variables like academic level, birth order and marital status influence motivation among students.

\section{Petroleum Technician Career}

Typically, petroleum technicians can work in the oil/gas field, laboratory and office [6]. Drilling technicians usually drill the earth's surface including ocean floors to extract petroleum. Loggers examine rock slices obtained from beneath the earth's surface and analyze the characteristics of various types of rocks. Production technicians gather petroleum samples from existing oil wells and regulate production. On the other hand, maintenance technicians ensure that all equipment and machines are operating normally.

It is important for petroleum technicians to carry out their tasks accurately and with great precision because even the slightest mistake can be dangerous or costly. Notably, petroleum technicians carry out physical tasks with potential risks [6]. Therefore, petroleum technicians involved in fieldwork must be healthy, flexible, strong and ready to work under unconventional conditions and during odd hours. Drilling technicians may have to live far from their homes for several weeks. Technicians working on offshore rigs may be forced to work within a constrained environment for long periods. Besides, petroleum technicians should be technology savvy since their work involves the use of scientific equipment, machines and even computers. Importantly, petroleum technicians should have proper sight and hearing ability with a good body as well as eye-hand coordination.

\section{Work Environment}

The work environment of petroleum technicians varies just as broadly as their tasks [6]. Depending on the nature of their tasks, petroleum technicians may be stationed on land or offshore. Furthermore, petroleum technicians may work in offices, laboratories, drilling sites or refineries. Production and drilling technicians' work may require them to travel to different parts of the world in search of petroleum. Often, they may find themselves in a rugged and unsafe environment including swamps, mountains or deserts. Petroleum technicians are exposed to many risks while at work. In a rugged environment, petroleum technicians are at risk of accidents such as falls and blowouts in wells where pressure is not well-regulated.

Additionally, petroleum technicians involved in exploration and development carry out various technical tasks during petroleum extraction and refinement [7]. In other words, petroleum technicians assist engineers to find the most effective of extracting and refining crude oil and natural gas. Many petroleum technicians are stationed at extraction and refinery sites.

\section{Skills Required}

An adequate understanding of sciences related subjects including chemistry, physics, and math is critical for individuals intending to become petroleum technicians [7]. Similarly, the ability to work under pressure and to solve sophisticated problems is also pivotal requirements for petroleum technicians. Finally, petroleum technicians require computer technical skills to facilitate design works associated with their work.

Scientists and engineers greatly rely on the support from petroleum technicians to adequately explore for natural resources available below the surface of the earth [8]. Petroleum technicians have practical experience since they spend most of their time in the field or in the laboratory where they collect and analyze data samples to ensure accurate monitoring of a site's status of oil/gas wells productivities. Figure 1 below makes it apparent that the annual salaries of petroleum technicians vary with their level of experience.

\section{Objectives of the Petroleum Engineering}

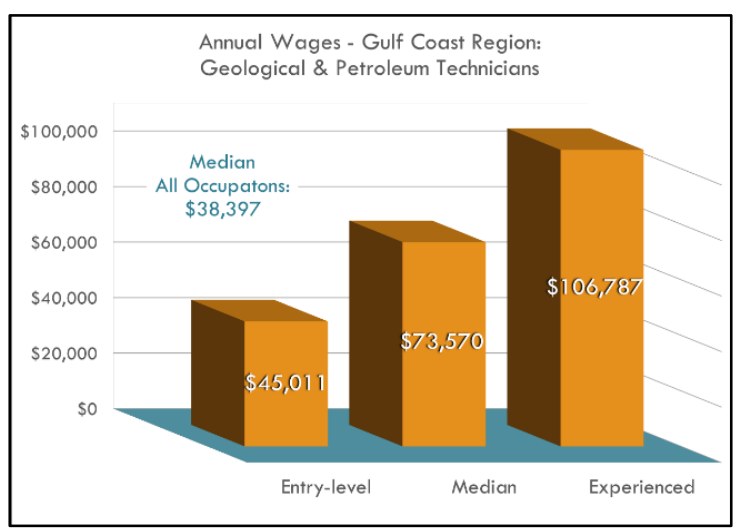

Figure 1 Petroleum Technicians' Annual Wages [8]. 


\section{Technology Department}

Petroleum Engineering Technology Department was created under the PAAET article number 581 of 16th April 2000. Since its formation, the department has graduated students and fulfilled various needs within the oil market.

Listed below is a summary of the department's objects.

- To offer students with adequate opportunities to acquire requisite practical workplace training in the oil industries.

- To reinforce the collaboration between the department and the Kuwait Oil Company through continuous education programs accorded to the company's workers.

\section{Exploration \& Development and Production \& Exporting Programs Taught in Kuwait}

Exploration and development, and production and transportation of oil and natural gas resources are some of the fundamental areas under the broadbased petroleum and natural gas engineering discipline. Notably, petroleum technicians within the petroleum industry work alongside the geologists and engineers to assist them in the laboratory, field and office. The College of Technological Studies designed the Exploration and Development, and Production and Exporting programs to offer appropriate training to high school graduates to acquire productive positions after successfully going through it. Graduation in the area of each program requires credit hours in various courses. Notably, the program mainly consists of major petroleum courses that requires up to 48 credit hours. Engineering support courses, petroleum major elective course, and free elective courses require 18,6 , and 3 credit hours respectively.

\section{Objectives of the Programs}

Exploration and Development program provides the provision of knowledge on physical and chemical laws and their use in the evaluation of real challenges. The Production and Exporting program covers petroleum and natural gas engineering which concerned with the production and export of the oil and gas resource. The petroleum industry requires engineering technologists to assist engineers and geologists in the field, laboratory and office. The College of Technological Studies has designed these programs to train high school graduates to enter productive position upon successful completion of the programs. Therefore, the design of Petroleum Technology Curriculum encompasses various educational objectives altogether in two main points:
- To provide students with the opportunity to experience the technology involving in petroleum industry.

- To provide students with hands-on-training dealing with the area of exploration and development or in the area of production and export.

\section{What is Petroleum Engineering?}

Petroleum engineering entails development, innovation, and exploration. Petroleum is a major source of fuel in the world. Petroleum engineering plays a key role in the way other professions undertake their tasks. There are various categories of petroleum engineers namely:

Reservoir Engineers: They ensure appropriate well location, high production rates, and improved production techniques to optimize overall oil production. Notably, these engineers also provide accurate estimates regarding the amount of oil and gas reservoirs through the study of their characteristics and determination of appropriate techniques of extracting these oil and gas resources from the reservoirs. Similarly, reservoir engineers also monitor various operations to promote maximum recovery of these oil, and gas resources from various reservoirs.

Drilling engineers: They are responsible for the management of the technical aspects of drilling trials, production, and injection of wells. Similarly, they consider various factors, such as cost factors to determine the most appropriate ways of drilling oil or gas wells. Drilling engineers also ensure safety, efficiency, and environmental preservation during the drilling process.

Production engineers: They work in collaboration with subsurface engineers to ensure appropriate management of the interface between the well and the oil and gas reservoirs. Notably, subsurface engineers ensure appropriate management of the interface between the reservoirs and the well involves establishing appropriate controls to ensure appropriate drilling process. After the wells have been successfully drilled, production engineers control the wells to monitor the well's oil and gas production. Production engineers are also responsible for coming up with appropriate approaches to improve the amount of oil and gas production in wells where production amounts fall short of expectations.

The roles of petroleum engineering graduates include:

- Evaluation of prospective oil and gas reservoirs

- Overseeing various activities that involve drilling and completing wells, production, and maintenance services.

- Selection and implementation of appropriate retrieval patterns 
- Designing of suitable surface collection and treatment facilities

The discussion above makes it apparent that the future of petroleum engineers has both opportunities and challenges that require the development and application of new technologies to appropriate recovery of oil and gas resources from the reservoirs. Recovery of hydrocarbon from various reservoirs such as from oil shales, tar sands, and offshore and gas fields requires the application of new recovery techniques to optimize oil and natural gas production. Petroleum engineers must also develop appropriate technologies to enhance recovery of oil resources left in the ground following the use of conventional oil production techniques to optimize well production.

Most oil companies operate across the world; therefore, petroleum engineers have opportunities for undertaking their duties across the globe. In this regard, they must have the ability to overcome the prevailing technological, political, and economic challenges in their international assignments. The synergic effect of these challenges makes petroleum engineering one of the most rewarding careers throughout the world. Geologists and petroleum engineers play critical roles throughout the lifetime of an oil and natural gas reservoir. Notably, field economics in petroleum production is a concerted effort of geologists and petroleum engineers through the determination of appropriate techniques for reservoir development and depletion. Therefore, petroleum engineering as a field requires adequate comprehension of related disciplines involved in oil exploration and production such as geophysics, petroleum geology and oil gas facilities among others. The projected growth in employment rates among petroleum engineers between 2014 and 2024 stands at 10 percent, which is faster than the average employment rate of other jobs. As more engineers approach retirement age, the job prospects for petroleum engineers will soon become favorable.

Employment growth in the oil industry depends on oil prices in the international market because most of the petroleum engineers work in oil and natural gas extraction companies; therefore, any change in oil prices is likely to impact their employment levels. Notably, an increase in oil prices can promote drilling in deep waters and other less hospitable locations as well as the application of new extraction procedures in existing wells. In this regard, it is evident that when oil prices go up, oil and gas companies are likely to engage in complex drilling operations that need additional engineers to help in every stage of the drilling operations thereby increasing employment opportunities for petroleum engineers in such organizations.

Similarly, as more petroleum engineers approach retirement, there will be an increasing need for the remaining engineers to be engaged only when there is a need. Therefore, there will be a growing demand for experienced petroleum engineers in bigger oil companies.
Several research papers have indicated the importance of people working in the oil and gas industry and have mentioned that they are the tread that hold the industry on the top [9]. Other agencies are promoting skill development programs to educate people at different levels [10]. Some engineering design courses in college are tailored to provide student with a realistic experience that will enhance the personnel to adopt to the work environment [11]. In order to prevent accident in the oil and gas industry fitness programs were provided in order to minimize injuries and minimize loss of time [12]. Other improvement to the people working in the industry will be given the safety management and workforce competence courses $[13,14]$.

\section{Analysis of Student Enrolment Data}

Figure 2 illustrates the number of students graduating from the Exploration and Development branch since its formation. Notably, between the years 2007 and 2018, it is evident that more students graduate in the fall semesters compared to spring semesters.

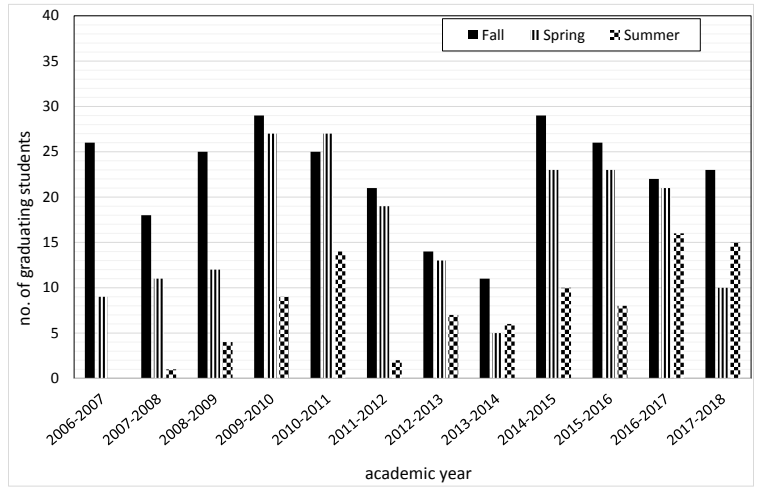

Figure 2 Graduates of each semester for the E\&D program

During to the two and half years (five regular semesters) required for graduation, it was observed that the rise in the number of graduates in the fall semester is partly because most high school graduates are enrolled in the program in the fall semester. Students, who fail to get enrolled during the fall semester because of low classroom capacities often get accepted during the spring semester. Notably, this explains why students graduating during summer are relatively low compared to those graduating from normal semesters.

The number of Production and Exporting student graduates from 2006 to 2018 is provided in Figure 3. The program shows a similar trend to students graduating in exploration and development.

A decline in the graduation number during the years 2011-2014 was due to stop accepting students for one year in both programs to minimize student-faculty ratio as seen in Figure 2 and Figure 3. 


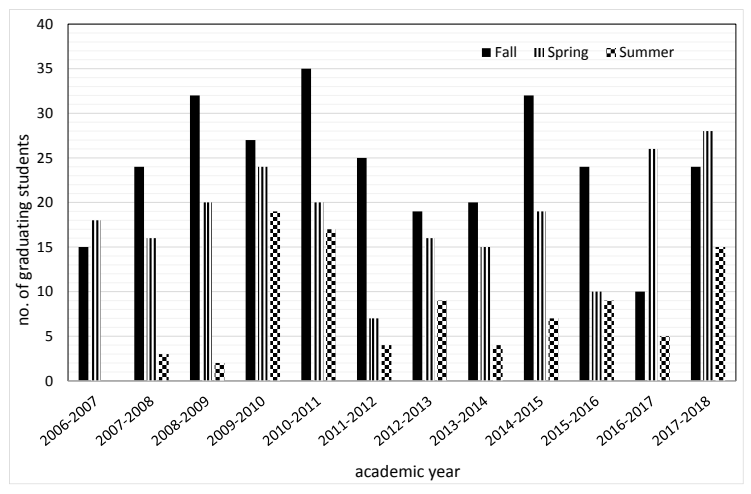

Figure 3 Graduates of each semester for the P\&E program

Figure 4 provides the number of students graduating from the petroleum technology department during the period between 2006 and 2018.

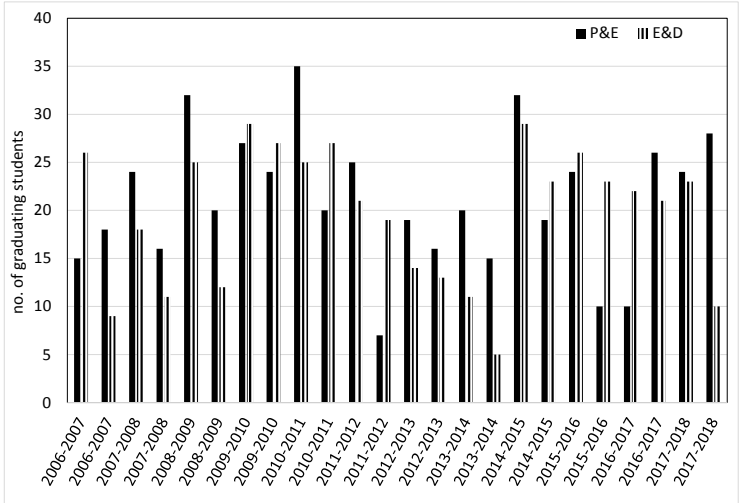

academic year

Figure 4 Graduates of Fall and Spring semesters for both programs

The figure makes it apparent that Production and Exporting graduates are higher than Exploration and Development graduates. Notably, this variation in the number of graduates in the two programs could be due to the workplaces available in Kuwait that promotes Production and Exporting Technology programs.

On the other hand, Figure 5 indicates the number of graduates from the petroleum technology department for both the majors in the program in comparison to the number of students graduating from the college of technological studies between 2006 and 2018. It shows that an average of 7 percent of petroleum technology department students graduated during the period compared to the total number of graduates from technological studies.

Table 1 indicates that about 5 to 10 percent of the graduates during the period compared to the total number of graduates from the college of technological studies enrolled for Production and Exporting programs. The total number of graduates from Exploration and Development programs ranges from 3 percent to 10 percent of the total graduates from the College of Technological Studies between the period of 2006 and 2018.

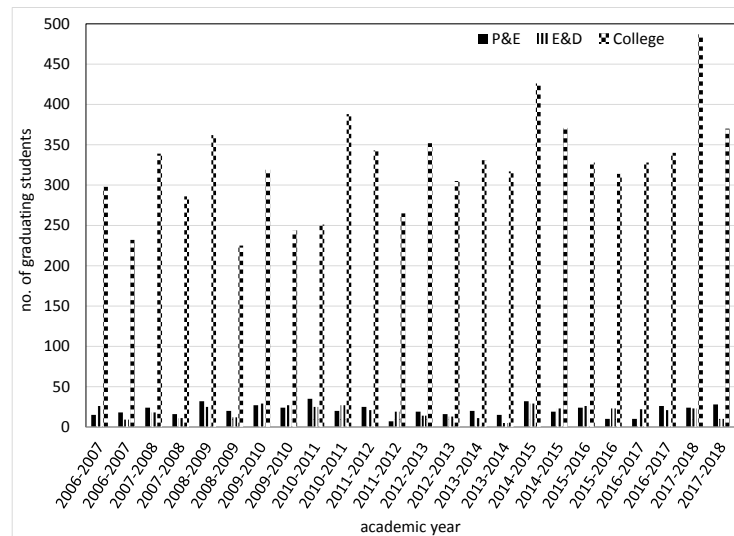

Figure 5 Graduates of Fall and Spring semesters for both programs compared to total college graduates

Table 1 Statistics of the graduates of the two programs (P\&E and E\&D) compared to the total graduates from the college.

\begin{tabular}{|c|c|c|c|c|c|}
\hline $\begin{array}{c}\text { Academic } \\
\text { year }\end{array}$ & $\begin{array}{c}\text { Graduate } \\
\text { (P\&E) }\end{array}$ & $\begin{array}{c}\text { Graduate } \\
\text { (E\&D) }\end{array}$ & $\begin{array}{c}\text { Graduate } \\
\text { (college) }\end{array}$ & $\begin{array}{c}\% \text { graduate } \\
\text { (P\&E) }\end{array}$ & $\begin{array}{c}\% \text { Graduate } \\
\text { (E\&D) }\end{array}$ \\
\hline $2006-2007$ & 33 & 35 & 530 & $6.23 \%$ & $6.60 \%$ \\
\hline $2007-2008$ & 43 & 30 & 670 & $6.42 \%$ & $4.48 \%$ \\
\hline $2008-2009$ & 54 & 41 & 658 & $8.21 \%$ & $6.23 \%$ \\
\hline $2009-2010$ & 70 & 65 & 668 & $10.48 \%$ & $9.73 \%$ \\
\hline $2010-2011$ & 72 & 66 & 753 & $9.56 \%$ & $8.76 \%$ \\
\hline $2011-2012$ & 36 & 42 & 741 & $4.86 \%$ & $5.67 \%$ \\
\hline $2012-2013$ & 44 & 34 & 811 & $5.43 \%$ & $4.19 \%$ \\
\hline $2013-2014$ & 39 & 22 & 780 & $5.00 \%$ & $2.82 \%$ \\
\hline $2014-2015$ & 58 & 62 & 973 & $5.96 \%$ & $6.37 \%$ \\
\hline $2015-2016$ & 43 & 57 & 793 & $5.42 \%$ & $7.19 \%$ \\
\hline $2016-2017$ & 41 & 59 & 861 & $4.76 \%$ & $6.85 \%$ \\
\hline $2017-2018$ & 67 & 48 & 1084 & $6.18 \%$ & $4.43 \%$ \\
\hline
\end{tabular}

Finally, Fig. 6 provides oil prices according to OPEC from 2004 to 2018. Notably, the figure makes it apparent that the oil prices had no impact on student enrolment probably because the college of Technological Studies is a state institution; hence, it acquires support from the States of Kuwait.

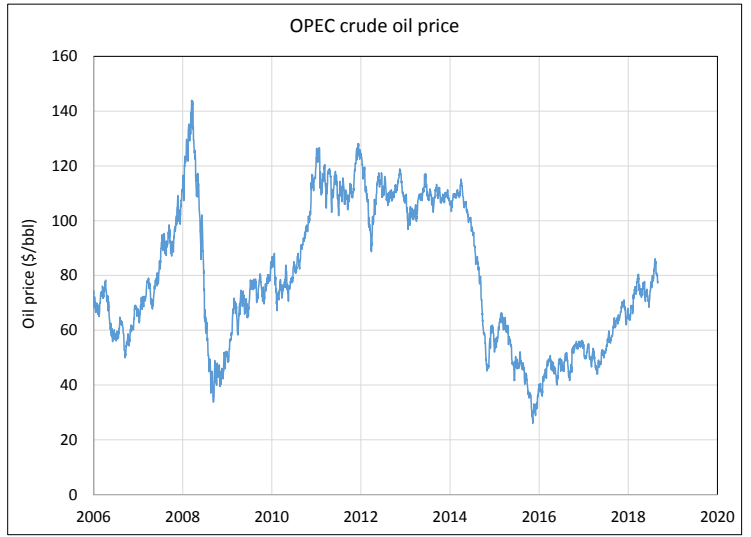

Figure 6 OPEC crude oil prices during the student enrolment analysis period

\section{Conclusions}

- The study of student enrolment in Petroleum Engineering Technology department in the College of Technological Studies makes it apparent that: 
- The number of students graduating from both programs in fall semesters between 2006 and 2018 is relatively higher compared to the number of students graduating during the spring semesters within the same period.

- More students graduated from the production and exporting program compared to those from exploration and development programs of petroleum technology between 2006 and 2018.

- Approximately 7 percent of students during the period between 2006 and 2018 graduated from the department of petroleum technology.

- About 5 to 10 percent of students taking production and exporting students graduated during the period compared to the number of graduates from the College of Technological Studies.

- About 3 to 10 percent of the total number of graduates from the College of Technological Studies were students undertaking exploration and development programs between the year 2006 and 2018.

- The number of students enrolling for various programs under the petroleum department remains the same regardless of variations in oil and gas prices.

\section{Funding sources}

This research received no external funding.

\section{Conflicts of interest}

There are no conflicts to declare.

\section{Reference}

[1] Al-Ali, S. 2013. Preparing Future Labour: An Assessment of the Standard of Graduates from the Public Authority of Applied Education and Training in Kuwait. Industry and Higher Education Journal. Vol. 27 No. 2, pp. 89-103

[2] Adam Ghazi Al-Otaibi. 1996. The Effect of Demographic Variables on Achievement motivation Among Kuwaiti Students at Kuwait University, Arab Journal of Administrative Sciences, 3:2-1996

[3] Indeed. 2017. Petroleum Engineering Technician salary in Houston, TX https://www.indeed.com/salaries/Petroleum+Engi neering+Technician-Salaries,-Houston\%2C+TX

[4] Bureau of Labor Statistics. 2015. Geological and Petroleum Technicians (May 2016), https://www.bls.gov/ooh/life-physical-and-socialscience/geological-and-petroleum-technicians.htm

[5] Stephanie Joyce, 2015, Falling Oil Prices Leave Petroleum Engineering Students Out in the Cold. Inside Energy. http://insideenergy.org/2015/02/13/falling-oilprices-leave-petroleum-engineering-students-outin-the-cold/
[6] http://career.iresearchnet.com/careerinformation/petroleum-technician-career/

[7] https://study.com/articles/Petroleum_Technician_ Career_Information_About_Becoming_a _Petroleum_Technician.html

[8] http://www.wrksolutions.com/forindividuals/career-exploration/geologicaltechnicians

[9] I. Percival, People Are the Thread That Hold This Industry Together, Journal of Petroleum Technology, Volume 59, Issue 10, 2007.

[10] R. Stephen, I. Haywood, Attracting and Developing the Best People, 4-7 September, Offshore Europe, Aberdeen, Scotland, UK, 2007

[11] T. Ertekin, R. P. Harris, P. J. Dudenas, Capstone Engineering Design Experience: Opportunities to Develop and Implement Skills that Work for Real People Doing Real Jobs, 19-22 September, SPE Annual Technical Conference and Exhibition, Florence, Italy, 2010.

[12] H. Mohamed, R. Donnelly, A. Fraser, Fitness to Work: A Risk-based Approach for the Oil and Gas Industry, 11-13 September, International Conference on Health, Safety and Environment in Oil and Gas Exploration and Production, Perth, Australia, 2012.

[13] R. J. C. Bonn, Work Force Competence, 9-12 June, SPE Health, Safety and Environment in Oil and Gas Exploration and Production Conference, New Orleans, Louisiana, USA, 1996

[14] H. D. Martin, Protecting People, Property, and Operations, 12-15 June, ASSE Professional Development Conference and Exposition, New Orleans, Louisiana, USA, 2005. 